PSYCHE.

CAMBRIDGE, MASS., JAN.-FEB. I888.

Communications, exchanges and editors' copies should be addressed to EDIToRs of PSYche, Cam. bridge, Mass. Communications for publication in Psyche must be properly authenticated, and no anony. mous articles will be published.

Editors and contributors are only responsible for the statements made in their own communications.

Works on subjects not related to entomology will not be reviewed in PsYche.

For rates of subscription and of advertising, see advertising columns.

\section{EDITORIAL NOTE.}

Unavoidable hindrances have so delayed the issue of volume four of Psyche that its publishers deemed it best to begin volume five with the year I888, omitting the years I 886 and 1887 . Volume five will include the years 1888 to 1890 . The concluding portion of volume four is now partly printed, but will still require considerable time for completion, on account of the expensive index which will accompany it.

\section{NOTE ON PELECINUS POLYCERATOR.}

In examining a considerable collection of Pelecinus polycerator I noticed that every specimen had the enlarged first segment of the abdomen split longitudinally on the back, on or near the median line. The split is sometimes a mere crack, sometimes a wide gap, and in the latter case is often somewhat torn at the ends.

This splitting has often been noticed by others, but I know of no published account of it. It has been suggested that it had some relation to the remarkable scarcity of the male in this species, but the more probable explanation seems to be in the warping caused in drying. Every collector knows how the parts of the ovipositor of the longtailed ichneumon-flies (Pimpla) warp in drying, and I have never noticed a crack in this place in the living $P$. polycerator, altho I have collected a great number of them.

\section{C: W: Woodworth.}

\section{FEEDING HABITS OF A LYCAENID CATERPILLAR.}

Last spring Mr. Lintner kindly guided me to his happy hunting grounds at Centre, near Albany, N. Y., where for the first time I had the pleasure of making the personal acquaintance of my namesake, Rusticus scudderii. I succeeded in obtaining from females enclosed on lupines a large number of eggs and in rearing many caterpillars to maturity.

The caterpillar has a very extensile head and flexible neck, as figured for $L$. pseudargiolus by Mr. W. H. Edwards, and its manner of feeding immediately after birth is rather remarkable; it first pierces the lower cuticle of the leaf, making a hole just large enough to introduce its minute head, and then devours all the interior of the leaf as far as it can reach - many times the diameter of the entrance-hole - so that when the caterpillar goes elsewhere, the leaf looks as if marked with a circular blister or pustule, having a central nucleus, the nearly colorless membranes of the leaf being all that is left at the blister, and at the central entrance to it the upper membrane only. The blister is $1.75 \mathrm{~mm}$. in diameter, and the nucleus-like opening to it only about $0.25 \mathrm{~mm}$. in diameter.

In later life the caterpillar feeds on both surfaces, though it still seems to prefer the under, but eats entirely through the cuticle of the surface on which it feeds, and down to the opposite cuticle which it leaves untouched. It retains, also, to some degree, its habit of thrusting its head between the cuticles to get at the juicier parts; and I have seen one bore out the cut end of a stem down to the rind on every side.

Samuel H. Scudder. 

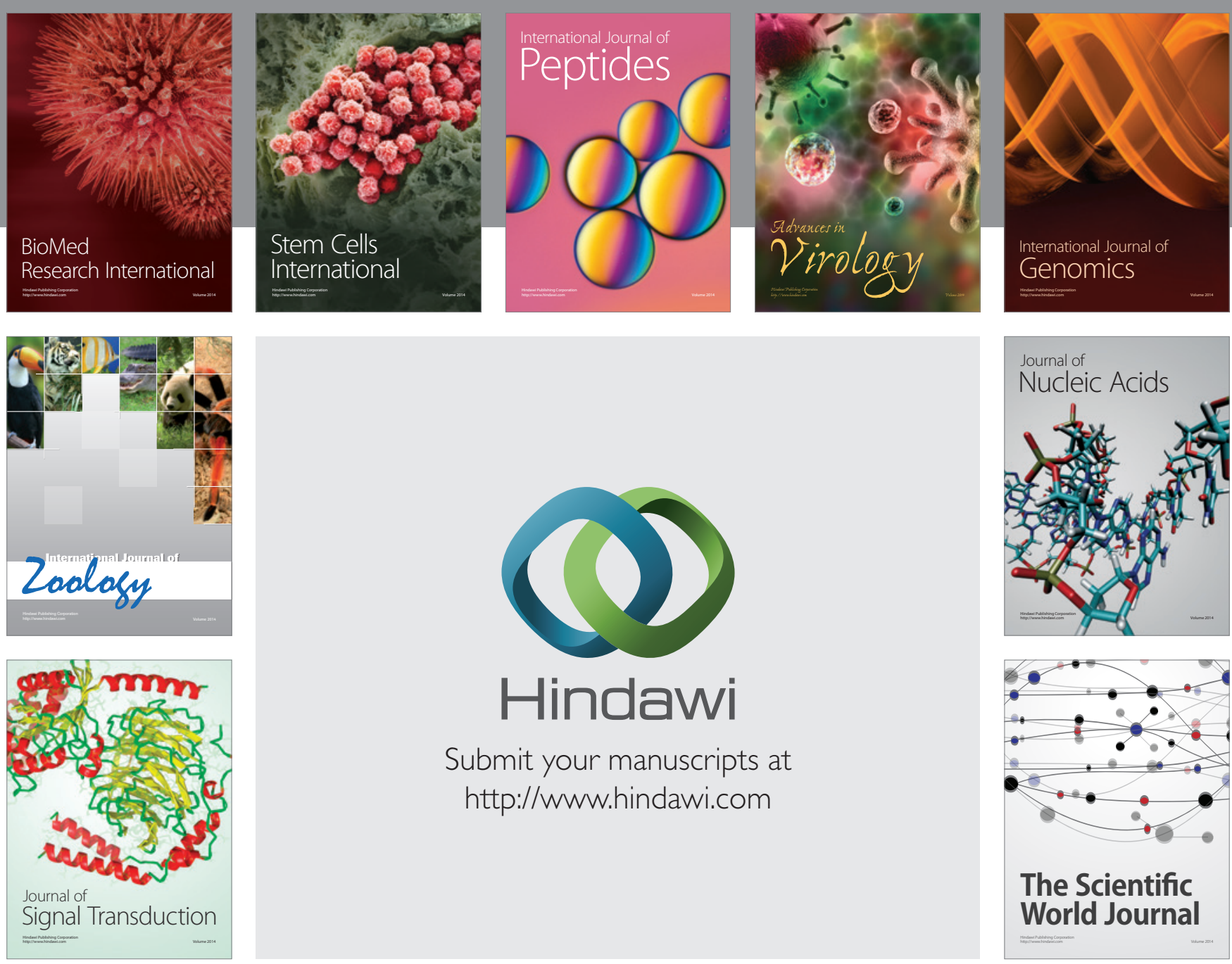

Submit your manuscripts at

http://www.hindawi.com
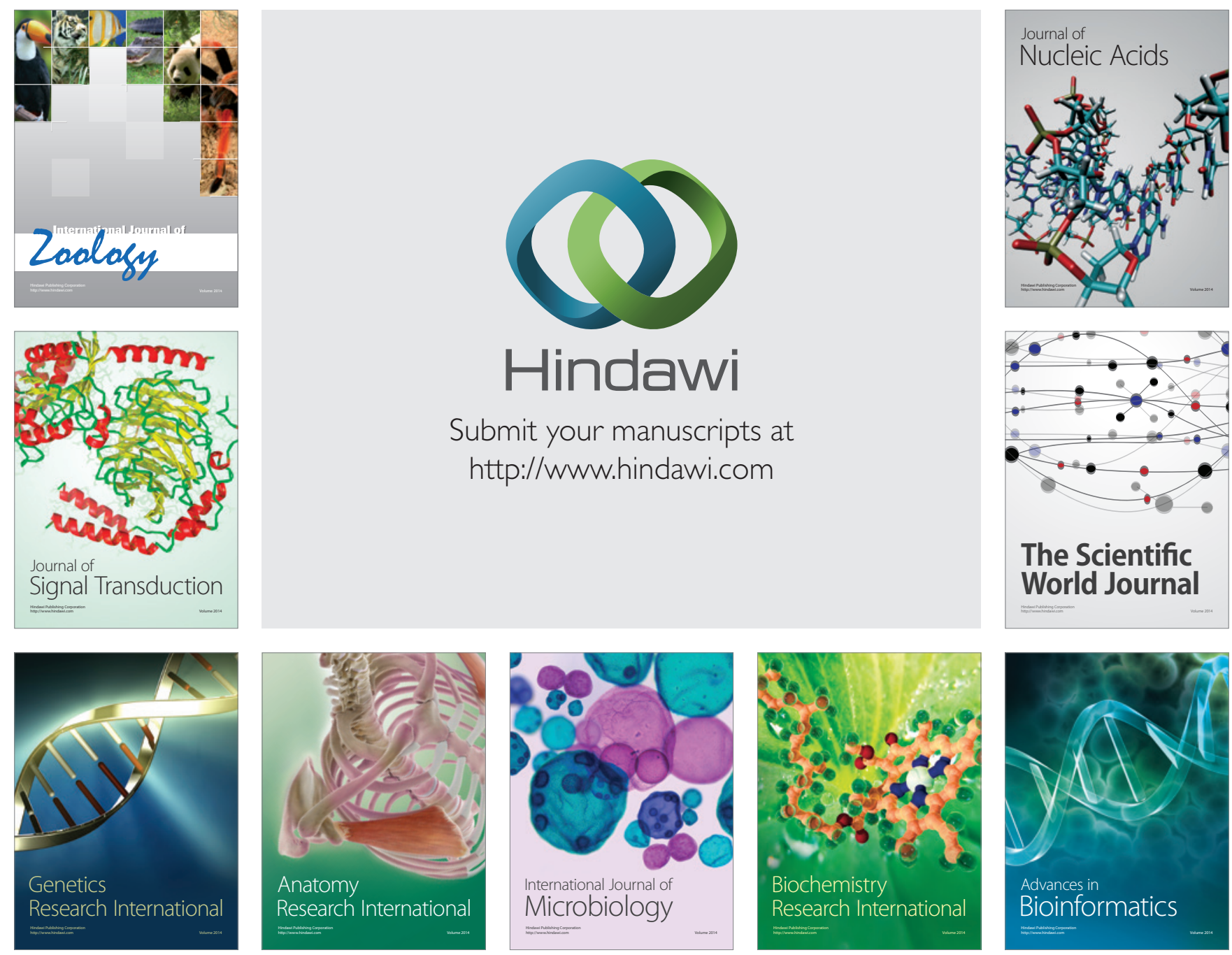

The Scientific World Journal
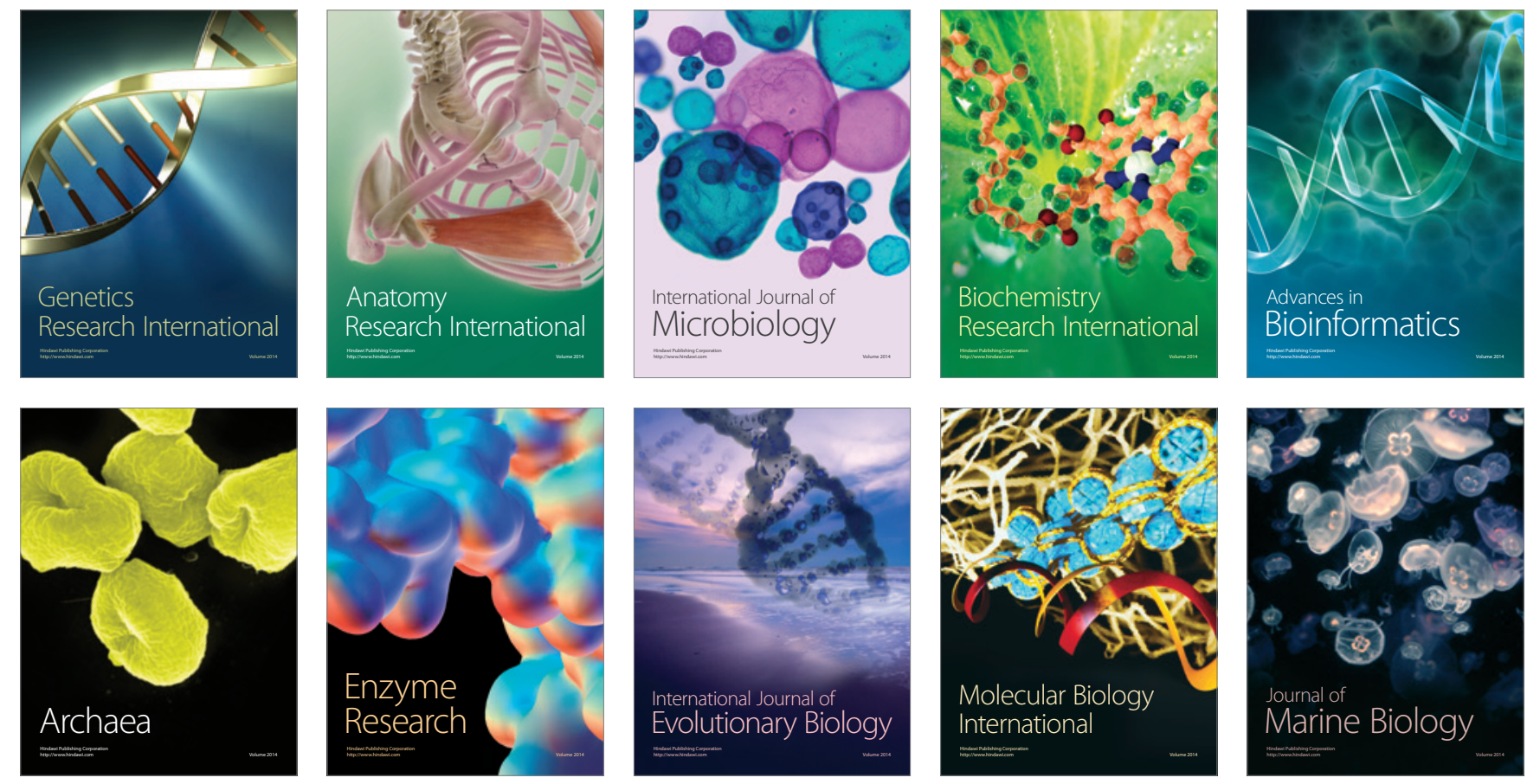